\title{
II Macrothink

\section{Objective and Goal Setting in Government Agencies in Nigeria and its Implications on Operational Outcomes}

\author{
Nwidobie Barine Michael \\ Department of Accounting and Finance, Caleb University, Lagos, Nigeria \\ E-mail: Barikem@yahoo.com
}

Accepted: March 5, 2012 Published: April 21, 2012

Doi:10.5296/ijld.v2i2.1668ＵRL: http://dx.doi.org/10.5296/ijld.v2i2.1668

\begin{abstract}
The design of corporate plans is hierarchical in nature with corporate objectives determining the specific achievable goals and strategies to achieve set objectives. Government agencies in Nigeria use established templates for setting specific goals followed by broad objectives for achieving the goals; explaining the non-achievement of results annually in contravention of the empirically tested pattern of objective setting, followed by specific goals setting and determination of strategies for achieving the set goals necessitating the reversal of the planning steps to broad objective setting, followed by specific goals setting for the achievement of the broad objectives and the deployment of necessary strategies to achieve the goals.
\end{abstract}

Key Words: Corporate Plan, Corporate Objectives, Corporate Goals and Strategies.

\subsection{Introduction}

A plan generally, is a specific commitment of organizations resources to specific counsel(s) of action growing out of the metal process of planning. If predetermines the course of action and deployment of emphasis and strategies to attaining objectives. Plan is the end product of the processing of determining what an organization is to do to remains in business, how to do it, when, where and who to do what in the organization. This course of action to be taken by any organization affects the entire firms; thus the decisions on such are to be taken by the top management and directors. This gives direction to the firms, moving it from where it is to where it ought to be. This transition requires deployment of huge resources, and strategies. Approval limits for this deployment are reserved for the board of Directors and the mangers. These accompanying decisions are taken by them.

Steiner (1969) developed companywide planning model incorporating three district types: Strategies or corporate plan, medium-term plan and short term plan. Strategies on corporate plans according to him is the function of the highest level of management by whom decisions 
on objectives of the organizations, policies and strategies that will govern the acquisition, use and disposition of resources to achieve objectives are made.

Objectives are the ends towards which activity is aimed. They represent the end point of planning and the aim of other organizational activities. They give direction to the nature of all major plans, which by reflecting these objectives, define the objectives of the major departments. Major objectives, in turn control the objectives of subordinate departments, and so on down the line. The objectives of lesser departments are better framed if sub-divisions managers understand the overall organizational objectives and the implied derivative goals. The decision of a corporate planning focuses on strategic issues, although some tactical aspects of management are involved. The end-point of corporate planning facilitate the co-ordination of activities, assists in the allocation of resources, and increase the organizations ability to cope with change. The process concerns the total resources and intended activities of the firm. It is about management of change. New methods, materials skirls, processes and techniques. Corporate plans cover all aspects of the firm's operation personnel, finance, productions, organization, marketing, management and control. According to Bennett (1994), it offers guidelines against which the performance of an organization may be assessed; the plan being a standard. It describes the activities and resources needed for intended operations, identifying possible new markets, application of new technology, and the likelihood of environmental change.

To Burton and Thakur (1995), organizations develop corporate plans for the attainment of strategic objectives. To them, a corporate is a statement of how the organization will utilize its resources and conduct its activities to achieve strategic objectives developed by top management and cover a long period of time. Its design has attendant uncertainties. Incorporation of these uncertainties into a corporate plan require making assumptions about threats and weaknesses of the organization.

The design of a corporate plan is hierarchal in nature with the corporate objectives determining corporate strategies, which in turn are supported by lower level strategies that cascade down the organization. This plan is designed to achieve the set objectives of the organization. Thus, the design of a corporate plan requires the setting of objectives to be achieved by executing the corporate plan. It also details the long-term goals of an organization and the available resources to achieve them. It specifies how the organization will achieve a competitive advantage, with profits and growth as necessary by-products. For efficient allocation of resources, the purpose for actions must be known. Organization's achievable objectives are those it desires to achieve with the specific goals detailing the achievable plans to achieve the broad objectives.

\subsection{Objective of the study}

The objective of this study is to determine the position of corporate objective setting in the design of corporate plans in government agencies in Nigeria and its implications on the agencies' operational outcomes. 


\subsection{Review of literature}

\subsection{Principles of corporate planning and design}

Corporate plan is a long-term plan describing how an organization intends deploying its total resources in order to achieve its mission. According to Bennett (1994), it deals with the mundane and instrumental measures for the efficient allocation of human, material, financial and other resources within the organisation; converting tactics and operational activities, the deployment of assets, allocation of duties and organization of work.

The execution of a corporate plan, involving the expenditure of organization's resources, must be directed towards receiving gains from its use. Government agencies are profit centres. Resources at their disposals are not for wastage but for use to generate income. The achievement of profit requires the efficient and effective use of financial, material, production and managerial resources. For each of these functional areas of an agency's activities, the input/output ratio of resources input to product performance output is set to optimize operation. These resources input to product/performance output ratio are the targets for each of the functional agencies' areas to achieve its target income. The functions' target input/output ratio and profit targets are the desires of the agency. These targets are called objectives (Bennett, 1994). He recommended that these objectives (targets) should be reasonable: neither over ambitions nor too low to discourage motivation.

Robbins and Coutler (1999) noted that the setting of objectives (targets) for an agency is a vital part of corporate planning. Without objectives to guide managers, they added, they will not know where or how to start the design of a corporate plan; and would not have anything to plan. Thus the definition of objectives is a prerequisite for effective and efficient design of a corporate plan.

The first step in planning according to Koontz et al (1980) is the establishment of objectives for the entire organization and then for each subordinate unit. Objectives specifying the results expected, indicate the endpoints of what is to be done, where the primary emphasis is to be placed, and what is to be accomplished by the network of strategies, policies, procedures, rules, budgets and programs. Bennett (1994) added that objectives give direction to the nature of all major plans, which by reflecting these objectives define the objectives of major departments. Major plans reflecting these objectives, in turn, control the objectives of subordinate departments, and so on down the line. The objectives of lesser departments are better framed if sub divisional managers understand the overall enterprise objectives and the implied derivative goals. All planning efforts are directed towards achieving organizational objectives. Invariably, objectives definition precedes goal setting and is an integral part of designing a corporate plan. The strategies to achieve established objectives are "numberised: in the corporate plan.

\subsection{Steps in designing corporate plans}

Weihrich and Koontz (1993) opined that preceding the designing of a plan for a government agency is the need of awareness by the agency of available opportunities in the business environment. Managers to them, should preliminary look at possible future opportunities, see them clearly and completely, know where their agency stand in the light of their strengths and weaknesses; understand what problems they wish to solve and why, and know what they 
expect to gain. It is on the result of this environmental scanning that government agencies' objectives can be set. The design of a corporate plan commences with the establishment of objectives for an entire agency specifying the expected results and end points of what is to be done; where the primary emphasis is to be placed, and what is to be accomplished by the network if strategies, policies, procedures, rules, budgets and programs. These objectives give direction to the corporate plans.

Secondly, managers according to them should establish, circulate and obtain agreement to utilize critical planning premises such as forecasts, applicable basic policies, and existing agency plans. These make up the assumptions upon which an agency's plan rests. Thirdly, managers to them should search for and examine alternative courses of action to achieve their objective especially those not immediately apparent. Fourthly, identified alternative courses of actions should be evaluated, weighing them in the light of premises and objectives. Fifthly, the best course of action should be taken making for the achievement of stated objectives. Sixthly, contingency and derivative plans should be developed with their own courses of actions and supporting plans. The selected courses of action to achieve organizational objectives should be "numberised". This serves as a standard for operations. This procedure is universally accepted by scholars and management practitioners as ideal for designing an agency plan. The design of a government agency's plan is two way: management top-down and bottom-up approaches. The top-down approach requires management to design and pass the plan to the strategic middle level management to use as a guide in the design of middle level plans. The down-top approach requires low level organizational plans to be developed, collated to make up the corporate plan.

In reality, the planning decisions are taken by the top management and passed to the middle level managers. Thus the down top eventually ends up top-down after approval.

\subsection{Composition and approaches to designing corporate plans}

Corporate plans are an all-encompassing design for an entire agency. It incorporates the objectives, strategies and plans of the functional areas of management, production, finance, marketing and personnel. Objectives and functional plans are set and designed for each of these areas and combined to make up the corporate plan. The Hoshin planning process developed in Asia is hierarchical in nature, with the corporate objectives determining the corporate strategies, which in turn are supported by lower level strategies that cascade down the organization. In effect, the goals of every individual level support the goals of the next level up in the hierarchy. Every strategy further consists of tactics or actions that need to be undertaken to accomplish the strategy. For the corporate planning to be effective, it must promote intra and inter programme co-operation i.e. the various departments in the organization need to support each other to achieve remarkable synergistic results.

The design of a corporate plan can be carried out either by the "gap" analysis or "what if" analysis methods. The gap analysis approach according to Bennett (1994) begins with the planner setting targets based on what he or she believes to be attainable in the longer term and then compare these targets with forecast, current activities; assuming current circumstances continues. Divergences are analyzed and measured, and measures devised to bridge the identified gaps. 
The "what if" approach requires the planner to ask series of questions to establish the various outcomes likely to result from different future environments. These outcomes are quantified in terms of expected sales, costs, expenditures, assets structures, flow of funds and other operational variables.

Whichever approach is employed, Bennett (1994) noted that the product of the design process should facilitate the coordination of activities, the transfer of resources, and the agency's capacity to cope with change. It should also set priorities for action, describing any changes in an agency's organization structure that might be required an implementable timetable. A minimum performance criterion for the plan to be satisfied before the plan can be regarded as a success, he added, must also be specified.

\subsection{Dynamism and time horizon of corporate plans}

Consensus on firm-wide objectives on the deployment of resources and action plans to achieve them culminate in the corporate plan. A corporate strategic plan may involve changing operational links, acquiring new equipments for use, recruitment, reorganization of operations, movement to new sites and raising huge capital to met these new obligations.

Corporate plans are developed using forecasts, judgments and assumptions about an increasingly uncertain future. These uncertainties are real and recognizable because forecasts and assumptions are shown as ranges of values rather than as single point estimates (Lucey, 1996). This inherent uncertainty, he added, also requires that plans be modified and adjusted in light of unexpected occurrences as such may have significant effect on the organization requiring constant plan review, reworking areas of discrepancies between actual and performances. This process was also recommended by the Hoshin planning process.

A corporate plan is the program of emphasis and development of resources to achieve corporate objectives. Objectives and future desired states. Corporate plans involve not only the expenditure of resources to achieve objectives but also the repayment of plan of borrowed funds obtained for financing the strategies.

Expenditures on strategic plans are capital intensive and take a long time to implement. Decisions to acquire new operational lines involve designing of new lines, receiving of quotation from vendors of these lines, its construction, implementation and testing take a long time to implement and may cover a period of five years and above.

Burton and Tharkur (1995) concluded from empirical studies that the time frame for corporate plan vary from one organization to another and from one industry to another. Meigs and Meigs (1993) collaborate this expected time frame of a corporate plan.

A government agency with a corporate plan is better equipped to face up to change, generating higher income from new opportunities. To Bennett (1994), large government agencies find the coordination between divisions enhanced when it designs corporate plans. Resources he added are allocated more efficiently and the agencies are able to monitor their actual rate of growth (or decline) against predetermined standards, and can arrange their operations coherently without conflicts in activity.

These benefits are unlikely to be realized unless the planning process is taken seriously by the senior management involved, and middle and junior management are committed to the strategic objectives established by the plan. Schermerhon (1989) added that designing a 
corporate plan brings stability to an agency, take care of contingencies, and improve performance.

Designing a corporate plan is tedious and must be painstakingly carried out for optimal results. Most senior managers are unable to cope with the complex information generated in a corporate planning process. Diverse forms of information, sales forecasts, written reports, efficiency audits, bar charts, Lorenz curves and statistical analyses are generated in the corporate planning process to which managers may not identify clear priorities for action (Bennett, 1994).

An approved corporate plan forms a standard for the organization. Standards are control points against which actual performances are gauged. Kreitner (1995), noted that while a corporate plan gets things headed in its tight direction, control keeps them headed in that direction. To him, the execution of a corporate plan requires the formulation of immediate and operational plans. To keep the organization in its chosen direction, corrective actions are necessary when preliminary or final results deviate from plan. Deviating activities in progress can be corrected before it is too late. Deviations between final results and plans are instructive feedback for the improvements of future plans.

\subsection{Methodology}

\subsection{Sampling, data collection and analysis}

Corporate objectives and plan documents of seven randomly selected government agencies: Nigerian Communications Commission, National Agency for Food and Drugs Control, Nigerian Civil aviation Authority, Federal Airport Authority of Nigeria, Standard Organisations of Nigeria, Federal Road Safety Commission and the Federal Inland Revenue Service; from seven ministries were obtained for the study. The corporate plans, plan procedures, objectives, and strategy settings and procedures with the deployment of operational and functional plans in these agencies were determined.

4.0 Research findings, implications on operational outcomes, and conclusions Research findings on the place of corporate objectives in the corporate plans of seven government agencies with constituted Boards of Directors shows that the specific goals of these agencies are set first, then followed by its broad objectives, and strategies to achieve the set goals and objectives in contravention of the empirically tested procedure of broad objective setting first, then goals setting and strategies to be deployed to achieve the set goals then objectives. Nigerian government agencies adopt this reverse procedural template explaining the perennial non-achievement any results. The broad objectives are pursued with allocated resources to achieve specific goals. This is a procedural anomaly. Objectives are general aims. The pursuit of first these general aims cannot lead to the achievement of specific goals but the achievement of specific measurable goal 1 , goal 2 , goal 3 to goal $n$ contribute to the achievement of the broad objectives.

A percentage of the objectives can be achieved by the achievement of specific numbers of goals at the end of the year which could be identified and measured. Though the Board of Directors set these goals and objectives, it adheres to the wrong procedural template of corporate plan design and without input from operational managers detailing the ability of the 


\section{Ml Macrothink}

agencies to achieve established goals and objectives. There is also a complete absence of supporting operational plans to the agencies' strategic plans.

\subsection{Recommendations}

To redress the above anomalies and improve objective and goal setting in government agencies in Nigeria:

(i) Broad objectives should first be set by these agencies, followed by specific achievable goals;

(ii) Tactical and operational managers should be involved in the corporate objectives setting so as to carry them along and input their contributions in objectives setting;

(iii) Clear and realistic targets should be set in the core functional areas of finance, marketing, production and operations to easily identify targets of each functional areas;

(iv) Staff should be encouraged to devise strategies management can employ in its operation to achieve agency objectives;

(v) Deployment of emphasis and resources for actions should be within the identifiable, strengths, weaknesses, opportunities and threat of the organization;

(vi) Accepted corporate plans must incorporate departmental plans of all units;

(vii) Realistic assumptions of macro and micro variables should be made for corporate plans; and

(viii) Approved corporate plans should be communicated to the staff detailing expected levels of performances necessary for the realization of the plan. 


\section{Macrothink

\section{References}

Bennett, R. (1994). The Kogan Page Guide to Effective Management. Kogan Page . London.

Burton, G. and Thakur, M. (1995). Management Today: Principles and Practice. Tata McGraw-Hill New Delhi.

Koontz, H. O; Donnell, C. and Weihrich, H. (1980). Management. McGraw-Hill. Tokyo.

Kretiner, R. (1995). Management ( $6^{\text {th }}$ Ed.) Houghton Mifflin. Boston.

Lawal, A. A. (1993). Management in Focus. Abdul Industrial Enterprises. Lagos.

Lucey, T. (1996). Management Accounting ( $4^{\text {th }}$ Ed.) Continuum. London

Meigs, R. F. and Meigs, W. B. (1993). Accounting: The Basis for Business Decisions. $\left(9^{\text {th }}\right.$ Ed.). McGraw-Hill. New York.

Nigeria communication strategic management plan 2004-2006. Retrieved from www.ncc.org.ng on 17/06/09.

Robins, S. P. and Coutler, M. (1999): Management ( $6^{\text {th }}$ ed). Prentice Hall New Jersey

Schermerhon, J. (1989). Management for Productivity. John Wiley. New York.

Steiner, G. A. (1969). Top Management Planning. Macmillan. New York.

Weihrich, H. and Koontz H. (1993) Management : A global perspectives . MCgraw - Hill New York 